Revista Nacional de

Gerenciamento de Cidades

pode ser transformado em uma série de outros produtos ou podem ser utilizados para outros fins segundo Flander e Rovers (2009).

As construções envolvendo o bambu como material estrutural têm sido estudadas, sobretudo em países onde dentro de um contexto histórico cultural, este já era utilizada com esta finalidade. Yu et al. (2011) realizaram estudos na China para comparar edificações com estrutura de bambu com as de tijolo e concreto a fim de saber as diferenças existentes na emissão de carbono e energia embutida nela. O protótipo de residência com estrutura de bambu integra a arquitetura tradicional com a tecnologia inovadora de isolamento com o objetivo de criar um modelo de casa apropriado ao futuro da China. A casa tem área de $52 \mathrm{~m}^{2}$ onde as vigas e pilares são de bambu e a ligação entre elas é feita com aço. Para melhor isolamento térmico, as fachadas são moduladas como uma estrutura-sanduíche. O estudo, realizado pelo método de avaliação do ciclo de vida, em inglês Life Cycle Assesment (LCA), revelou que o uso do bambu na estrutura da edificação reduz em $11 \%$ o uso de energia e em $18,5 \%$ na emissão de carbono ao longo do seu ciclo de vida uma vez que a tecnologia de isolamento utilizada tem menor energia e carbono embutidos comparado às construções de tijolo e concreto.

Ghavami (2004) realizou ensaios comparativos entre o bambu e materiais comumente encontrados na construção civil, como o aço e a madeira. Constatou-se que a produção de $1 \mathrm{~m}^{3}$ de aço que possui uma mesma resistência, requer 50 vezes mais energia que o bambu. Sua tensão de ruptura à flexão pode alcançar $151 \mathrm{MPa}$. Em termos estruturais foram testados, limite elástico, tensão de ruptura, módulo de elasticidade $(E)$, além de sua densidade $(\rho)$ em relação às madeiras comumente utilizadas na construção civil. $O$ autor concluiu que o bambu além de apresentar propriedades físicas e mecânicas favoráveis apresentou em alguns casos desempenho mecânico superior à madeira.

A pesquisa consiste na construção de módulos de painéis de vedação em escala real feitos com estrutura de bambu e fechamento com placas de partículas orientadas, OSB. O sistema construtivo flexível pode ser adaptável a vários tipos de 
fechamentos através de sua modulação e padronização dimensional a fim de gerar um desempenho mecânico de acordo com as normas vigentes. Os procedimentos de fabricação dos painéis de vedação em bambu e os resultados para resistência à compressão excêntrica e impacto de corpo mole serão apresentados.

\section{PAINÉIS DE VEDAÇÃO}

Segundo Santos e Aguilar (2007), o grupo de pesquisa em Habitação (Habis) do Instituto de Arquitetura e Urbanismo de São Carlos (IAUSC), estudaram três tipos de painéis de vedação pré-moldados: painel colchão de ar, painel terrapalha monolítico e terra-palha bloco. Os painéis desenvolvidos tem dimensão de 100 $\mathrm{cm} \times 240 \mathrm{~cm}$, construídas por revestimento interno em lambris, esqueleto em Pinus com ligações feitas por chapas com dentes estampados, chapa de aglomerado, chapa de aglomerado, terra-palha em bloco ou terra-palha monolítico; sarrafos para fixação das tábuas; tábuas para revestimento externo; mata-juntas para o acabamento nas frestas das tábuas; e tela, utilizada apenas para ligação entre os elementos de terra-palha e a ossatura (Figura 1).

Figura 1. Composição da parede do sistema de vedação painel terra-palha bloco. 1.

Revestimento interno; 2. Ossaturas; 3. Blocos de terra-palha; 4. Sarrafos; 5. Tábuas de peças de madeira de Pinus tratadas; 6. Mata-juntas; 7. Tela.
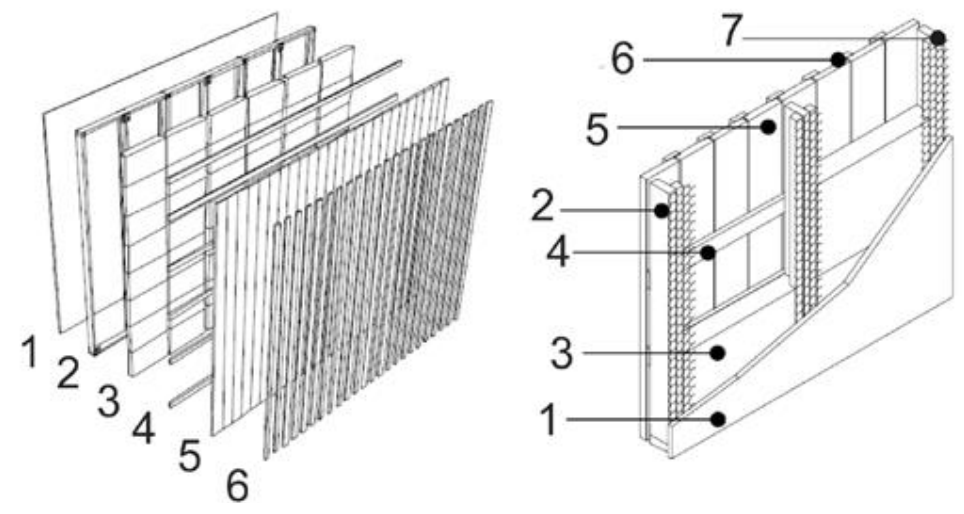

Fonte: SANTOS, 2007. 


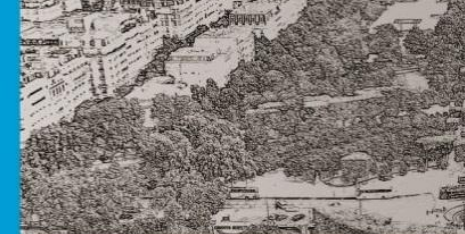

\section{Revista Nacional de}

Gerenciamento de Cidades

Em Minas Gerais foi desenvolvido um painel tipo sanduíche em Eucalipto, no Curso de Arquitetura e Urbanismo da Pontifícia Universidade Católica, o projeto foi baseado no sistema de vedação painel colchão de ar, mostrado por Navarro e Ino (1998) citado por Santos e Aguilar (2007), mas difere em alguns aspectos construtivos como o material utilizado, feito de Eucalipto, dimensões de $100 \mathrm{~cm} \mathrm{x}$ $300 \mathrm{~cm}$, e a substituição da chapa de aglomerado por uma manta impermeável visando a redução de custo e o peso do painel conforme Figura 2.

Figura 2. Composição dos painéis sanduíche e vista do sistema construtivo em madeira.

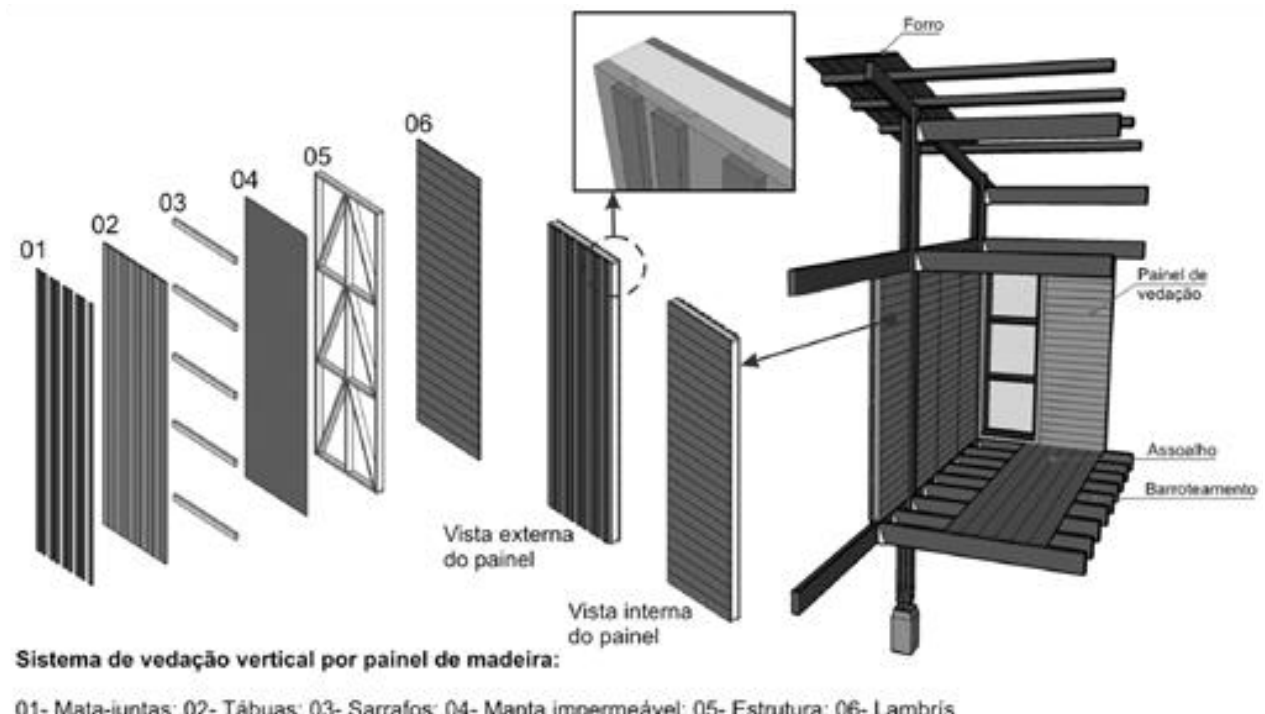

Fonte: SANTOS, 2007.

Com o objetivo de desenvolver um painel de fechamento lateral para instalações rurais Sartori et al. (2012) desenvolveram em sistema modular estrutural em madeira de reflorestamento e chapas de partículas de bagaço de cana-deaçúcar e resina poliuretana bicomponente à base de óleo de mamona produzidos no Laboratório de Construções e Ambiência, FZEA/USP-Pirassununga. A obtenção da chapa de partículas a partir do bagaço da cana-de-açúcar se deu pelo processo de moagem e para sua adesão foi utilizada a resina poliuretana bicomponente à base de óleo de mamona. A estrutura do painel foi construída com vigas de madeira de 


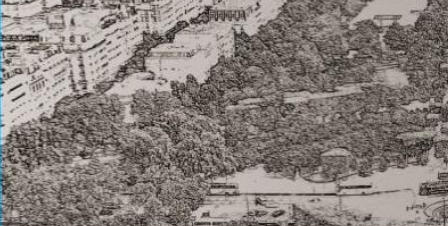

\section{Revista Nacional de}

Gerenciamento de Cidades

reflorestamento do gênero Eucalyptus. Na construção do protótipo foram utilizados quatro painéis fixados na estrutura de madeira com parafusos, formando uma peça com dimensões 2,20 m de comprimento e $52 \mathrm{~cm}$ de largura (Figura 3).

Figura 3. Desenho do protótipo com suas dimensões (a), ilustração do protótipo estrutural em madeira e painéis de partículas (b)

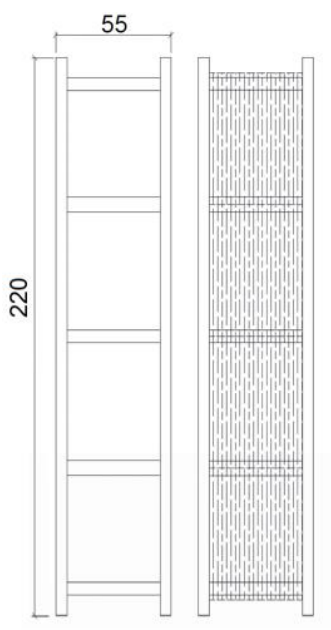

(a)

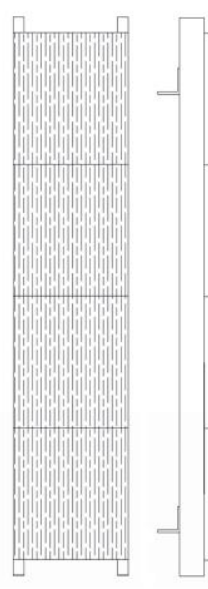

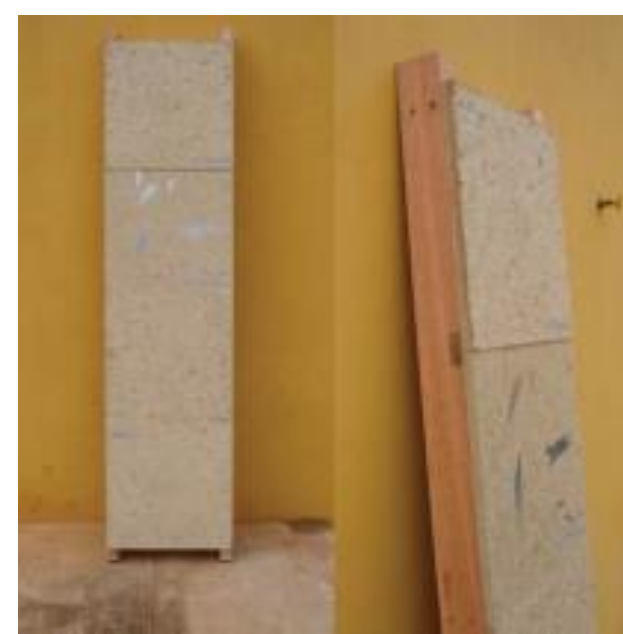

(b)

Fonte: SARTORI, 2012.

Foram realizados os ensaios mecânicos de Impacto de corpo mole segundo as normas NBR 11675 e ensaios de acordo com a NBR 15575 - Edifícios habitacionais de até cinco pavimentos - Desempenho. No ensaio foram aplicadas diferentes intensidades de forças e aferido o deslocamento sofrido pelo componente construtivo. Os resultados obtidos mostraram que para o deslocamento de corpo mole o protótipo apresentou deslocamentos horizontais aceitáveis, dentro dos limites estabelecidos pela norma. Sendo assim, o sistema modular com madeira de reflorestamento e painéis de partículas é indicado para as instalações rurais de manejo para bovinos.

Segundo Pereira e Beraldo (2007) foi construída uma casa de bambu em Bauru, SP. As paredes foram feitas com painéis trançados de lascas retiradas do colmo de Bambus tuldoides, com camada dupla coberta externamente por uma 
Revista Nacional de

Gerenciamento de Cidades

camada de reboco e tinta e internamente a trama de bambu foi deixada exposta (Figura 4). Os autores afirmam que na Colômbia e no Equador o bambu é utilizado na forma de esteira, para isso, o colmo é golpeado na direção longitudinal, mas sem rompê-lo totalmente. Feito isso, o colmo é aberto e a porção interior é retirada pela maior concentração de amido. Então as esterillas, como são chamadas, são fixadas em quadros pré-fabricados de madeira formando uma camada dupla, e por fim elas são revestidas com argamassa. Em 1999 foi construída pela Faculdade de Engenharia Agrícola da Unicamp (Feagri) uma edificação similar ao método anterior utilizando apenas uma camada de bambu, cobertas com piche como preservativo e areia a fim de aumentar sua aderência com a argamassa.

Figura 4. Casa de Bauru (a); Vista interna da casa de Bauru (b) e (c).

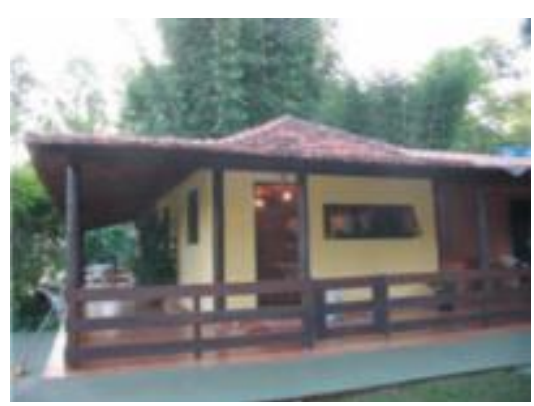

(a)

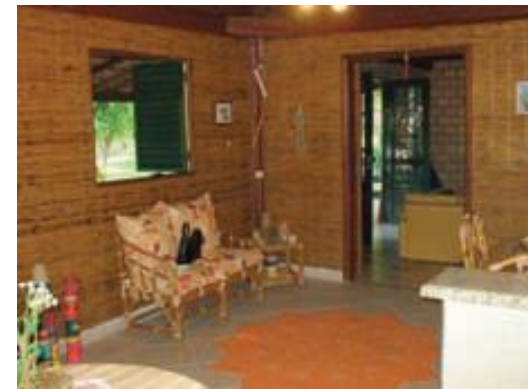

(b)

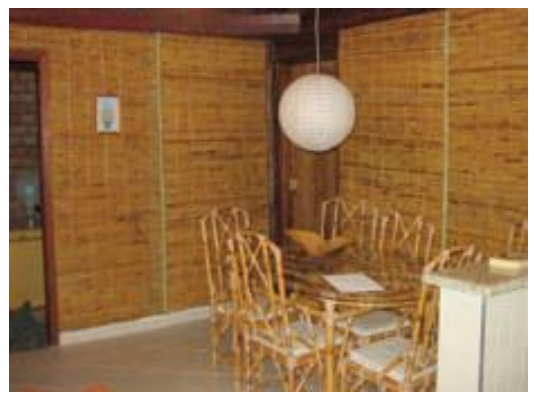

(c)

Fonte: PEREIRA e BERALDO, 2007.

Segundo Silva (2004) o comportamento estático dos painéis é dado pelos caminhos percorridos pelas ações verticais (peso-próprio e sobrecarga) e horizontais (eólicas e sísmicas) até a base da fundação. As ações verticais são dadas pelo carregamento permanente e pela sobrecarga de utilização que atuam na estrutura do piso e da cobertura e são transmitidas até a fundação pela compressão dos montantes. Devido a essas ações devem ser consideradas, no desempenho das edificações, a restrição aos deslocamentos de translação, rotação e deformação da estrutura. 
Albermani et al (2006), compararam as características estruturais de duas espécies de bambu. Para isso foram realizados testes de compressão e flambagem nas espécies Phyllostachy bambusoides (PB), que apresenta cor verde e Phyllostachy pubescens (PP) de cor marrom-amarelada. Os colmos utilizados tinham em média 3 a 6 anos de idade, com diâmetro externo de 50 a 65 mm e cerca de 1,50 m de altura. Foram preparados 28 exemplares para teste, sendo catorze de cada tipo (PB e PP). Para cada espécie foram realizados 8 testes de compressão e 3 de flambagem. Os testes revelaram que as propriedades de ambas as espécies de bambu obtiveram resultados satisfatórios para uso estrutural.

\section{CONFECÇÃO DOS PAINÉIS EM ESCALA REAL}

Os painéis fabricados, com dimensões de 550 × $2200 \mathrm{~mm}$, foram compostos pela estrutura principal em bambu roliço e pelo painel de fechamento em ambos os lados formando assim um componente com ar confinado em seu interior, com espessura total de $12 \mathrm{~cm}$. Para a análise mecânica foram construídos três corpos de prova em escala real para determinação da resistência à compressão excêntrica. Foram utilizadas chapas de OSB com dimensões de 1220 × $2440 \mathrm{~mm}$ na fabricação dos painéis.

\section{PREPARO DO MATERIAL E MONTAGEM}

Para o início das atividades foi realizada a colheita dos colmos de bambu na área agrícola da Universidade Estadual Paulista (UNESP), em Bauru. Os bambus plantados nesta área são manejados, marcados com letras de acordo com sua idade e sua colheita se dá apenas quando os bambus chegam a idade de 5 anos, onde apresentam a máxima resistência e o diâmetro desejado para a realização das atividades. 


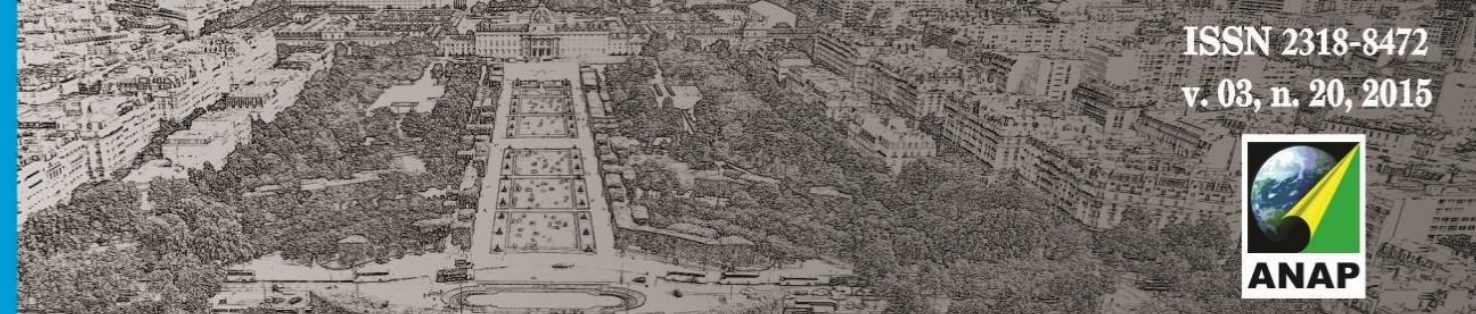

\section{Revista Nacional de}

Gerenciamento de Cidades

montantes para a inserção e fixação das barras roscadas do interior dos banzos. Os banzos e os montantes foram encaixados e fixados com parafusos auto atarrachantes pelo exterior, e pelo interior através das barras roscadas. Cada painel é formado por dois montantes e cinco banzos, sendo que todos os encaixes são fixados exteriormente por parafusos auto atarrachantes e, interiormente, apenas três dos cinco banzos, são fixados pelas barras roscadas intercaladas entre si. Realizada a ossatura do painel, as chapas de OSB são encaixadas e fixadas com parafusos auto atarrachantes em ambos os lados.

A partir da coleta, tratamento e secagem dos colmos com $10 \mathrm{~cm}$ de diâmetro, eles são cortados com comprimento de 2,20 m para a fabricação dos montantes e 0,46 m para a fabricação dos banzos. A ligação entre eles é feita através do encaixe boca-de-peixe, reforçados com parafusos, além disso, o primeiro, o terceiro e o último banzo são presos por meio de barras roscadas, como elemento de ligação entre os montantes e o banzo. $O$ fechamento do painel foi realizado com chapas de OSB, com espessura $1 \mathrm{~cm}$, fixados à estrutura com parafusos conforme os detalhes figura 7 .

Figura 7. Montagem da ossatura (a), parafusos auto atarrachantes (b) e painéis armazenados (c).
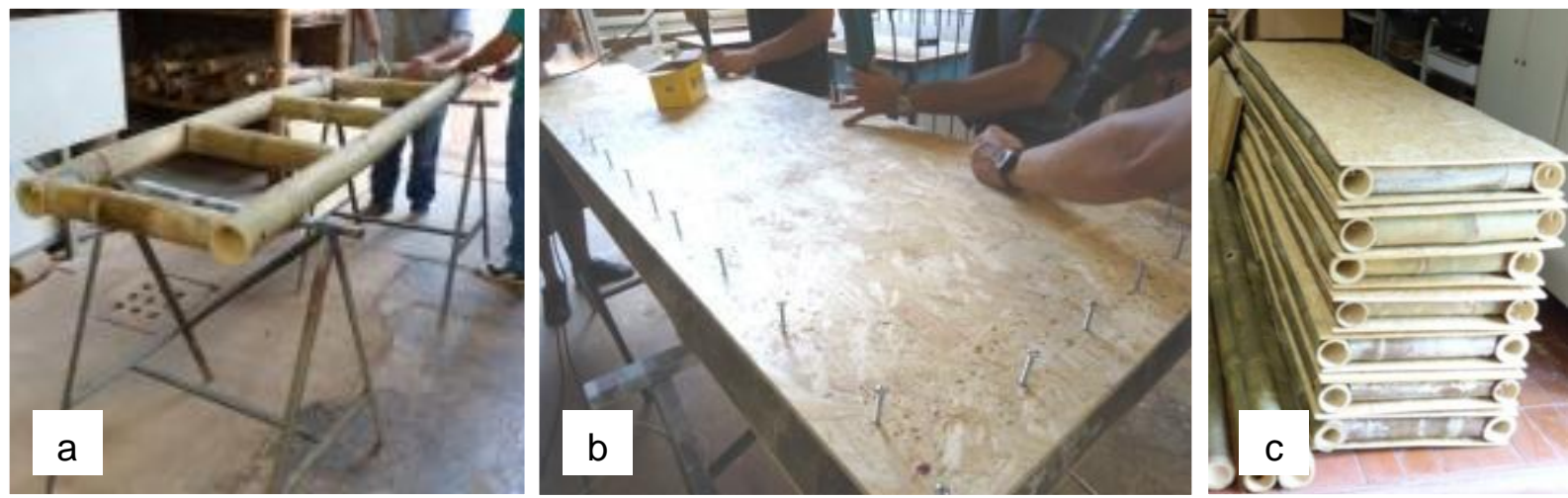

Fonte: o autor, 2014 
Revista Nacional de

Gerenciamento de Cidades

\section{AVALIAÇÃO DO DESEMPENHO DOS PAINÉIS EM ESCALA REAL}

Para a determinação da resistência à compressão excêntrica nas divisórias leves internas moduladas foram realizados ensaios de acordo com a norma NBR 11680 (1990). O corpo de prova, neste ensaio, é constituído por um painel nas condições normais de uso. Instalou-se então o painel no equipamento de ensaio e, sempre o mantendo aprumado, utilizou-se o perfil "l" para a transmissão de carga, obedecendo a excentricidade de $1 / 6$ da espessura. Foi instalado um defletômetro no centro de cada face de cada painel (Figura 8).

No procedimento de ensaio, a carga foi aplicada de maneira lenta e gradativa a cada $200 \mathrm{~N}$ da provável carga de ruptura, sendo esta muito mais detalhada, com leitura maior de pontos em relação à recomendação da norma que solicita leituras em patamares de $1 / 10$ a 1/15 para obtenção de um número significativo de pontos para o traçado da curva carga $x$ deslocamento horizontal. A norma recomenda também que para cada incremento de carga o carregamento fosse estabilizado durante 5 minutos para então proceder à leitura dos deslocamentos, o que não foi necessário uma vez que a leitura foi realizada digitalmente, com grande precisão. O corpo de prova foi inspecionado visualmente para serem registradas as eventuais avarias, tais como, fissuras, esmagamentos e estilhaçamentos. Foram fabricados vários painéis (Figura 7c), entretanto, utilizaramse três amostras (painéis estruturais) para avaliação da resistência à compressão excêntrica.

Para avaliação estrutural, em peças de tamanho real, é comum manufaturar um número reduzido de exemplares em função do tempo de preparo das amostras em laboratório. 


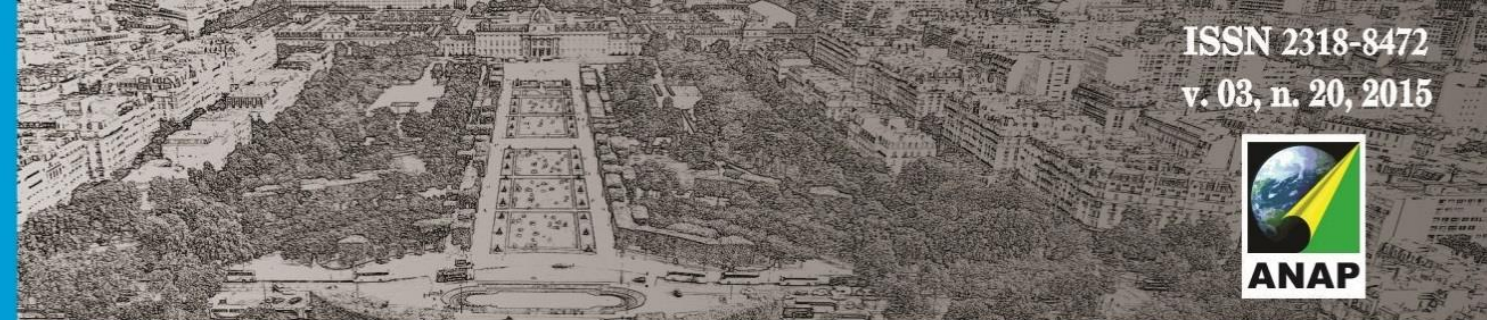

\section{Revista Nacional de}

Gerenciamento de Cidades

Figura 8. Esquema de ensaio à compressão excêntrica (A), instrumentação (B), posição dos deslocamentos (C) e defletômetro posicionados no centro (D).
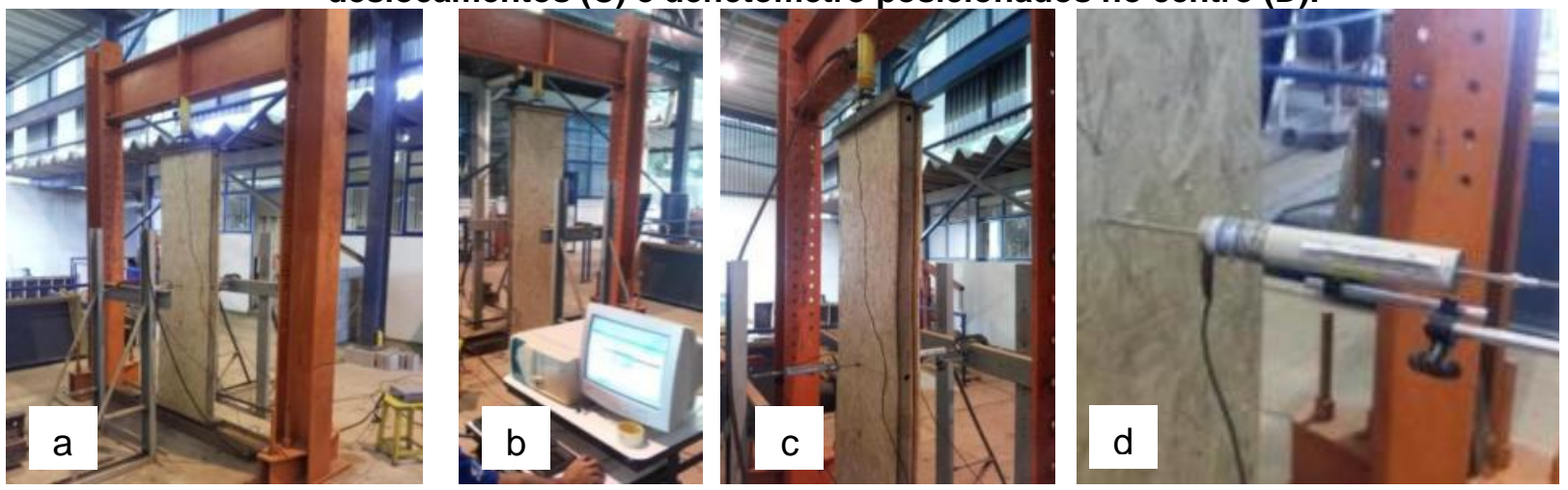

Fonte: o autor, 2014

A Figura 9 apresenta o diagrama de tensão $\mathrm{x}$ deformação para determinação da resistência à compressão excêntrica para os três painéis testados.

Figura 9. Diagrama tensão $x$ deformação para determinação da resistência à compressão excêntrica.

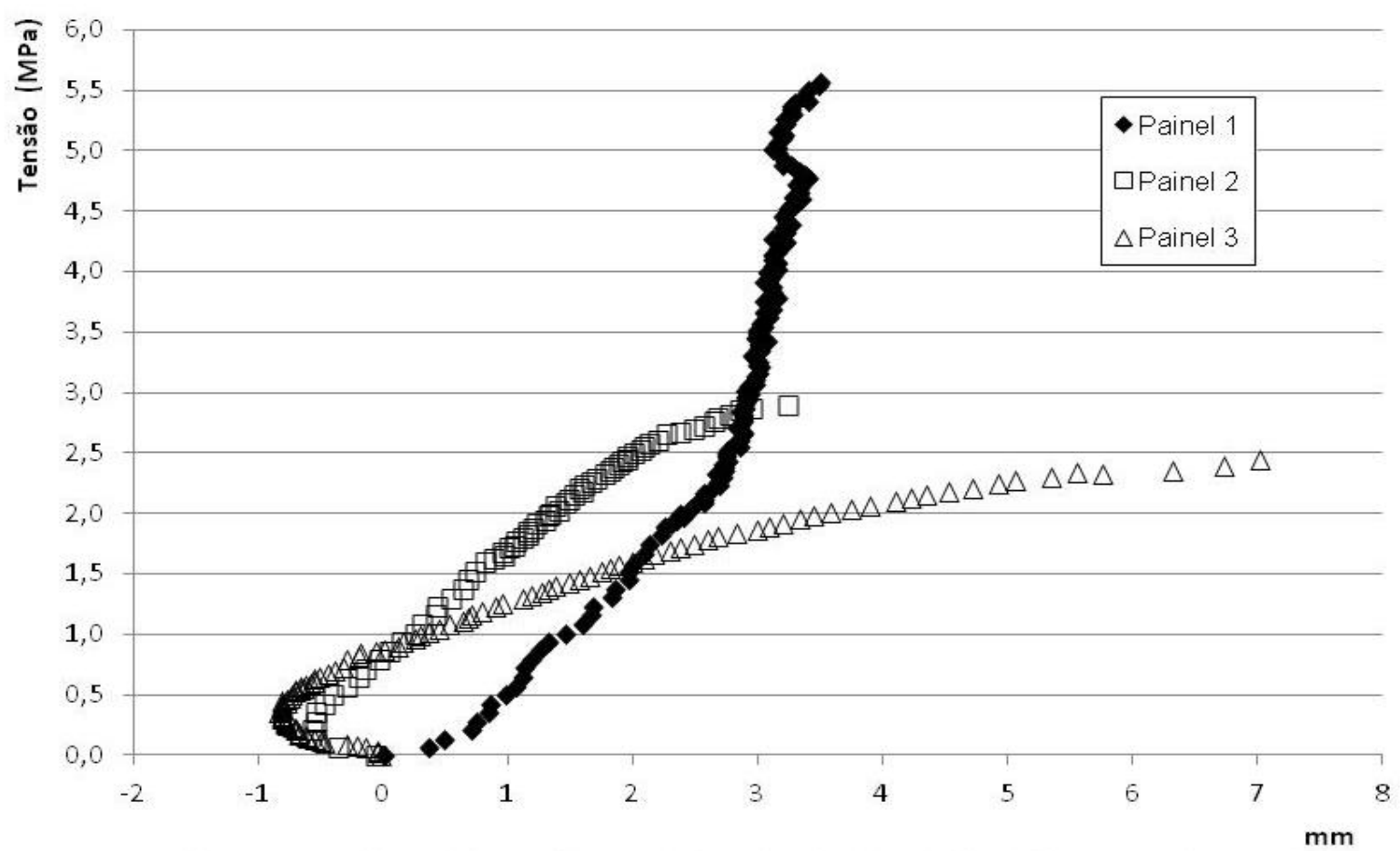

Fonte: o autor, 2015.

De acordo com o diagrama (Figura 9) pode-se notar que 0 Painel 1 comportou-se de forma atípica em relação aos demais, com uma tensão de 5,54 

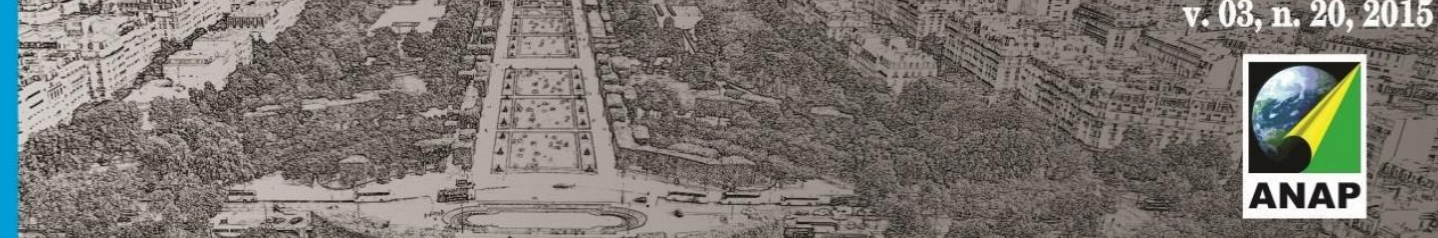

Revista Nacional de

Gerenciamento de Cidades

MPa e aproximadamente 2,8 $\mathrm{mm}$ de deformação, esta semelhante aos demais painéis no trecho linear. O Painel 2 comportou-se de forma semelhante ao Painel 3 , mas com menor deformidade, de aproximadamente $3,3 \mathrm{~mm}$ com tensão de 2,89 $\mathrm{MPa}$. No Painel 3 observa-se com o aumento da carga excêntrica uma deformação aproximada de $7 \mathrm{~mm}$ no instante da ruptura com tensão de 2,44 MPa.

A carga de ruptura do painel 1 mostra que a montagem é capaz de suportar cargas maiores que aquelas atingidas nos ensaios dos painéis 2 e 3 . A variabilidade característica de materiais lignocelulósicos pode ter influenciado nos resultados obtidos. Não se encontrou valores de referência na literatura para comparar os resultados obtidos nesta pesquisa. Os painéis foram inspecionados visualmente e registradas as eventuais avarias. Ocorreram esmagamentos na base e no topo dos painéis. Além disso, observou-se o embutimento dos parafusos, ruptura do painel de OSB, arrancamento de parafusos e fissuras nos colmos de bambu nos três painéis avaliados.

\section{VERIFICAÇÃO DA RESISTÊNCIA A IMPACTOS}

Para a verificação da resistência ao impacto dos painéis em escala real, foram realizados os ensaios da norma NBR 11675 para divisórias leves internas moduladas. Neste ensaio, o painel de dimensões 0,55 $\mathrm{m} \times 2,20 \mathrm{~m}$ sofre repetidos golpes por um corpo mole. Foi utilizado um transdutor digital ao invés de utilizar o dispositivo de registro gráfico com um lápis como foi proposto pela norma, uma vez que, o modo digital possibilita a obtenção dos dados com maior precisão. O resumo das deformações máximas nos pontos de impacto do corpo mole é apresentado na Tabela 2. A Figura 10 apresenta o esquema dos ensaios de impactos de corpo mole em painéis. 


\section{Revista Nacional de}

Gerenciamento de Cidades

Figura 10. Esquema dos ensaios para resistência a impactos de corpo mole em painéis.

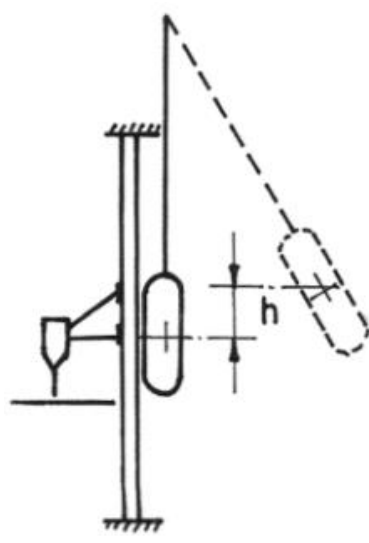

(a)

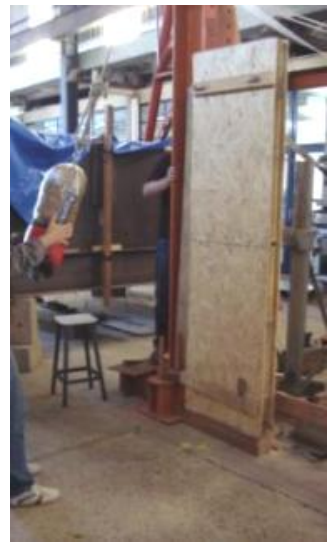

(b)

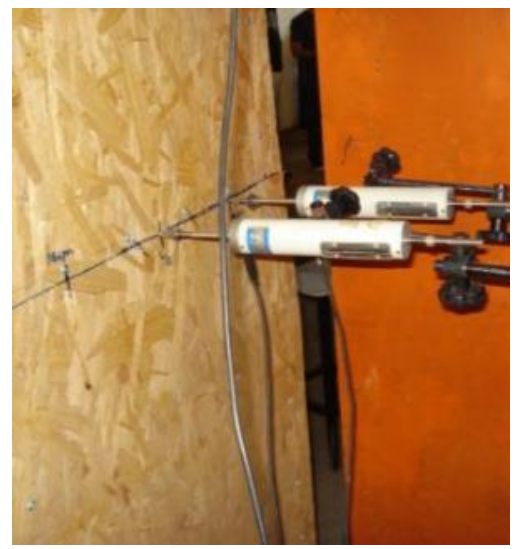

(c)

Fonte: (a) NBR 11675; (b) e (c) o autor (2014).

Tabela 2. Deformações máximas em milímetros nos pontos de impacto do corpo mole.

\begin{tabular}{|c|c|c|c|}
\hline Altura & Impacto & Ponto A & Ponto B \\
\hline $15 \mathrm{~cm}$ & $1^{0}$ & $(4,78 ;-1,51)$ & $(4,91 ;-0,57)$ \\
\hline $30 \mathrm{~cm}$ & $\begin{array}{l}1^{0} \\
2^{0} \\
3^{0}\end{array}$ & $\begin{array}{c}(9,39 ;-1,78) \\
(10,53 ;-1,92) \\
(10,97 ;-2,00)\end{array}$ & $\begin{array}{c}(6,44 ;-1,96) \\
(10,49 ;-1,92) \\
(9,31 ;-0,88)\end{array}$ \\
\hline $30 \mathrm{~cm}$ & $\begin{array}{c}1^{\circ}, 2^{\circ} \text { e } 3^{\circ} \\
\text { Consecutivos }\end{array}$ & $\begin{array}{c}(10,81 ;-0,99) \\
(6,73 ;-0,63) \\
(7,72 ;-1,96)\end{array}$ & $\begin{array}{c}(10,03 ;-1,13) \\
(6,54 ;-0,92) \\
(9,01 ;-1,57)\end{array}$ \\
\hline $45 \mathrm{~cm}$ & $\begin{array}{l}11^{0} \\
2^{\circ} \\
3^{\circ} \\
\end{array}$ & $\begin{array}{c}(9,88 ;-0,06) \\
(9,01 ;-2,09) \\
(12,86 ;-0,40) \\
\end{array}$ & $\begin{array}{c}(6,55 ;-2,19) \\
(11,76 ;-0,46) \\
(7,77 ;-2,00) \\
\end{array}$ \\
\hline $45 \mathrm{~cm}$ & $\begin{array}{c}1^{\circ}, 2^{\circ} \text { e } 3^{\circ} \\
\text { Consecutivos }\end{array}$ & $\begin{array}{c}(9,18 ;-0,12) \\
(11,92 ; 0,88) \\
(11,88 ; 2,87)\end{array}$ & $\begin{array}{l}(8,51 ;-1,58) \\
(2,38 ;-1,15) \\
(4,65 ;-0,98) \\
\end{array}$ \\
\hline
\end{tabular}

A norma não estabelece um valor de referência para deformação obtidas no ensaio de impacto para avaliar se as deformações encontradas são aceitáveis. Não se encontrou valores de referencia na literatura para comparar com os resultados obtidos. Entretanto, existe um forte indicativo da qualidade dos painéis confeccionados, por não ocorrer avarias para as alturas estabelecidas pela norma.

Os ensaios foram conduzidos com uma altura de $45 \mathrm{~cm}$, acima dos valores 


\section{C}

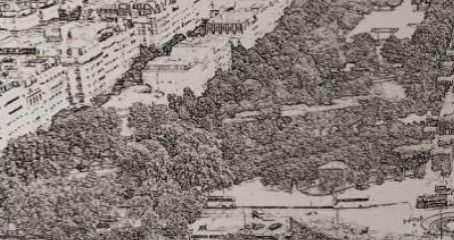

Revista Nacional de

Gerenciamento de Cidades

normativos, com o objetivo de verificar deformações para cargas mais elevadas. Para altura de $45 \mathrm{~cm}$ no Ponto A e B ocorreram pequenas deformações e avariais somente no painel de OSB, sem deformação nos colmos de Bambu.

\section{CONCLUSÃO}

Em função da Política Nacional de Incentivo ao Manejo Sustentado e ao Cultivo do Bambu, conforme Lei no 12.484, de incentivo a pesquisa e o desenvolvimento tecnológico voltado para o manejo sustentado, cultivo e das aplicações do bambu, de suas fases de transformação e de comercialização dos produtos derivados do Bambu faz-se necessário pesquisas voltadas ao assunto. A pesquisa apresentou de forma satisfatória os procedimentos de construção de módulos de painéis de vedação, em escala real, feitos com estrutura de bambu e fechamento de com placas de partículas orientadas, OSB. O estudo traz subsídios para constituir os valores máximos de referência de 5,5 $\mathrm{MPa}$ de resistência à compressão excêntrica e valores de deformações máximas em milímetros no Ponto A $(12,86 ; 2,87)$ e no Ponto $B(11,76 ; 2,19)$ de impacto de corpo mole em módulos de painéis de vedação em Bambu. Portanto, para este avaliação os resultados foram satisfatórios.

As dificuldades de utilizar o Bambu estão relacionadas com o manejo, extração e preparo das peças para qualquer finalidade de aplicação. Existe na área agrícola da UNESP FEB bambuzais com idade de colheita. Entretanto, para pesquisas com cunho experimental em iniciação científica é preciso ter atenção especial aos prazos propostos, pois, a usinagem e a montagem dos painéis de Bambu demandou expressivo tempo. As opiniões, hipóteses e conclusões ou recomendações expressas neste material são de responsabilidade dos autores e não necessariamente refletem a visão da FAPESP. 


\section{AGRADECIMENTOS}

À Fundação de Amparo à Pesquisa do Estado de São Paulo (FAPESP) pelo apoio financeiro (processo oㅡ 2012/16448-8).

\section{REFERÊNCIAS}

ALBERMANI, F.; GOH. G.Y.; CHAN, S.L. Lightweight bamboo double layer grid system. Engineering Structures, v. 29- n.7, p.1499-1506, 2006.

ASSOCIAÇÃO BRASILEIRA DE NORMAS TÉCNICAS. NBR 11675 - Divisórias leves internas moduladas - Verificação da resistência a impactos - Método de ensaio. Rio de Janeiro, 2011. 6p.

ASSOCIAÇÃO BRASILEIRA DE NORMAS TÉCNICAS. NBR 11680 - Divisórias leves internas moduladas Determinação da resistência à compressão excêntrica. Rio de Janeiro, 1990. 3p.

ASSOCIAÇÃO BRASILEIRA DE NORMAS TÉCNICAS. NBR 15575 - Edificações habitacionais Desempenho. Parte 1: Requisitos gerais. Rio de Janeiro, 2013. 71p.

BRASIL. Lei $n^{\circ}$ 12.484, de 8 de setembro de 2011. Dispõe sobre a Política Nacional de Incentivo ao Manejo Sustentado e ao Cultivo do Bambu e dá outras providências. Diário Oficial [da República Federativa do Brasil], Brasília, DF, Ano CXL VIII, v.174, n. 1, 09 set. 2011. Seção I, p. 01-02. Disponível em: < http://www.planalto.gov.br/ccivil_03/_ato2011-2014/2011/lei//12484.htm >. Acesso em: 23 jun. 2015.

FLANDER, K.; ROVERS, R. One laminated bamboo-frame house per hectare per year. Construction and Building Materials, v.23 - n.1, p.210 - 218, 2009.

GHAVAMI, K. Bamboo as reinforcement in structural concrete elements. Cement and Concrete Composites, v.27, n.6, p. 637-649, 2004.

PEREIRA, M. A. R.; BERALDO, A. L. Bambu de corpo e alma. 1ª Edição. Bauru, SP: Canal6, 2007. $240 p$.

SANTOS, M. P.; AGUILAR, M. T. P. Painéis de madeira como vedação vertical em construções. Cadernos de Arquitetura e Urbanismo, v.14 - n.15, p.242-263, 2007.

SARTORI, D. L.; CRAVO, J. C. M.; BARRERO, N. G.; FIORELLI, J.; JUNIOR, H. S. Painel em Madeira de Reflorestamento e Chapas de Partículas para Instalações Rurais. Floresta e Ambiente, v.19-n. 2, p.171 - 178, 2012.

SILVA, A. Comportamento diafragma de paredes de madeira no sistema leve plataforma. Dissertação de Mestrado, Faculdade de Engenharia Civil, Universidade Federal de Uberlândia, 2004. $142 p$.

YU, D.; TAN, H.; RUAN, Y. A future bamboo-structure residential building prototype in China: Life cycle assessment of energy use and carbon emission. Energy and Buildings, v. 43-n10, p.26382646, 2011. 